\title{
Prevalence of Dental Fear and Anxiety among Russian Children of Different Ages: The Cross-Sectional Study
}

\author{
Maria Sarapultseva1,2, Maria Yarushina ${ }^{1,2}$ Igor Kritsky² Roman Ibragimov ${ }^{2} \quad$ Alexey Sarapultsev ${ }^{2, \odot}$ \\ ${ }^{1}$ Department of Pediatric Dentistry, Medical Firm Vital EVV, \\ Ekaterinburg, Russia \\ 2Institute of Immunology and Physiology, Ural Branch, Russian \\ Academy of Sciences, Ekaterinburg, Russia

\begin{abstract}
Address for correspondence Alexey Sarapultsev, DSc, MD, Institute of Immunology and Physiology, Ural Division of Russian Academy of Sciences, 106 Pervomayskay Street, 620049 Ekaterinburg, Russia (e-mail: a.sarapultsev@gmail.com).
\end{abstract}

Eur J Dent:2020;14:621-625

\begin{abstract}
Objective Children's dental fear may lead to an avoidance of seeking dental care or disruptive behavior during treatment. The study was aimed to evaluate the prevalence and scores of dental fear and anxiety (DFA) among Russian children of different ages with an experience of dental treatment.

Materials and Methods The cross-sectional study included 371 children aged 2 to 17 years. Study participants were divided into three groups according to their age: 112 "preschool children" aged 2 to 5 years, 137 "school children" aged 6 to 11 years, and 122 "adolescents" aged 12 to 18 years. The questionnaires were distributed at reception areas of the dental clinic to parents of children aged 2 to 5 years and to the older children themselves.

Statistical Analysis Data analysis was performed using SPSS version 15.0. The parametric tests were used (one-way ANOVA, Student's t-test, and Pearson's correlation) because of the expected sample of more than 100 observations. The chi-square test was used for categorical variables.

Keywords

- anxiety

- children

- dental fear

- DFA

- prevalence

Results The data have shown that $93.8 \%$ of the Russian child population visiting dental offices suffer mostly from moderate (11.85) levels of DFA. DFA was more often revealed in girls and among the youngest children aged 2 to 5 years.

Conclusions According to the obtained results, children were more afraid of "tooth drilling" and an "injection of local anesthetic" than other factors mentioned in the questionnaires. Fear of dental treatment is common among Russian children, and the factors associated with it differ with the gender and age of the child.
\end{abstract}

\section{Introduction}

According to Klingberg and Broberg (2007), dental fear is a normal emotional reaction to one or more specific threatening stimuli in the dental situation, while dental anxiety denotes a state of apprehension that something dreadful is going to happen in relation to dental treatment. ${ }^{1}$ With that, these terms are used interchangeably within the dentists, and thus, the term dental fear and anxiety (DFA) was proposed to refer to any strong negative feelings associated with dental treatment among patients whether or not the specific criteria for the diagnosis of those states were met. ${ }^{1}$

Children's DFA is a dynamic process that depends on many different factors, such as age, gender, maternal dental fear, unbearable pain during the first dental visit, and even the sweet consumption frequency. ${ }^{2,3}$ With that, the associations of DFA prevalence with age and sex are not almost clear. It is considered that younger children and girls have higher odds of displaying negative behavior, and that girls usually have higher rates of severe dental fear than boys. ${ }^{2,4,5}$ 
The prevalence of DFA considerably varies from 6 to $20 \%$ in European children ${ }^{6}$ to 20 to $50 \%$ in Asian children ${ }^{7}$ or takes intermediate values of 28 to $31 \%$ in all areas. ${ }^{8}$ The observed diversity in prevalence rates is due to the variety of the methods used in DFA calculations as well as the modulating effect of culture on the expression of DFA. ${ }^{9}$

DFA results in avoidance of behavior and lack of compliance, which are associated with higher caries complications and the need for oral rehabilitation. ${ }^{10,11}$ Moreover, DFA can determine the formation of vicious circles leading to future avoidance or delay of dental visit with a deterioration of oral health which consequently reinforces the dental fear. ${ }^{12}$ Thus, considering the interconnection between the DFA and oral health status, there is an urgent need for further research, estimating the DFA prevalence of revealing its contributing factors.

The purpose of this study was to evaluate the prevalence and scores of DFA in Russian children with an experience of dental treatment. The null hypothesis was that DFA is independent of the child's gender and age.

\section{Materials and Methods}

\section{Study Design}

This is a cross-sectional study and the Strengthening the Reporting of Observational studies in Epidemiology (STROBE) guidelines were followed in reporting this study. ${ }^{13}$ The study was conducted from January to December 2019 in Vital EVV dental clinic in Ekaterinburg, Russian Federation with a population of $\sim 1,483,000$ inhabitants and a Human Development Index of 0.824 at the time data were collected.

The study included children aged 2 to 17 years with no confounding medical and/or psychological history and neuropsychiatric disabilities with the experience of dental treatment following the results of medical history (form 043/y), whose parents/guardians gave written consent to take part. This study excluded patients older than 18 years (age of majority in Russia), with a negative experience in dental treatment following the results of medical history, or with a history of coronary heart disease, pre-excitation syndromes, motor impairments (cerebral palsy and epilepsy), with pacemakers, drug addicts, and dialysis patients. The patients whose parents/guardians did not consent to participate in the study were also excluded.

Study participants were divided into three groups according to their age: "preschool children" from 2 to 5 years, "school children" from 6 to 11 years, and "adolescents" from 12 up to 18 years. ${ }^{14}$

The questionnaires were prepared without the name of the candidate, and participation in the study was optional. At the top of the questionnaire, the phrase "participation in the study is optional" was inserted, which constituted consent.

The study was performed following the rules of the Declaration of Helsinki of 1975, revised in 2013. Ethical approval \# C-30-01-2019 (January 30, 2019) was obtained from the Institute of Immunology and Physiology of the Ural Division of Russian Academy of Science, Ekaterinburg, and informed consent was obtained from all parents or legal guardians of the subjects recruited for the study. A representative of the research team approached families to ask if they would be willing to have a research coordinator speak to them about the study. If yes, the coordinator spoke with the family, described the study (risks/ benefits, voluntary participation, and procedures). Families were given adequate time to reflect on the information, had any questions answered, and gave free and voluntary consent. Patient consent forms and the questionnaires were distributed to parents and pediatric patients older than 6 years at reception areas of the dental clinic. Requested information included the name and date of birth of pediatric patient; name, relationship with the patient, and legal basis for an adult to consent on behalf of a minor; acknowledgment by the patient or parent/guardian that all questions were answered; and signed by the dentist, parent or legal guardian, and witness.

\section{Sample Size Calculation}

To refute or prove the null hypothesis, using $\mathrm{G}^{*}$ Power 3.1, the following analyses were performed: one-way analysis of variance (ANOVA) for three age groups, Student's $t$-test to compare two groups of respondents by gender, chi-square test to find the issue that contributed most to DFA, and Pearson's correlation to find the relationship between $\mathrm{df}$ and age. To find the required sample size, preliminary calculations were performed on 137 respondents. Based on these calculations, to achieve a significance level of $p=0.05$ and a power of $80 \%$ ( $1 \beta=0.80$ ), the required sample size was 369 people.

\section{Survey Instrument}

The Russian version of the Modified Dental Anxiety Scale (MDAS) was used in the study. ${ }^{15,16}$ The MDAS is a widely used five-item instrument for self-rating dental fear showing validity evidence, high internal consistency, and reliability over time. ${ }^{17,18}$ In MDAS questionary, each question has five answers with corresponding scores for each answer ranging from 1 (not anxious) to 5 (extremely anxious). The scores for each of the five questions were added to calculate a total dental anxiety score value. Children with a total MDAS score of 19 or more have been considered to be very high anxious, 15 to 18 anxious, 11 to 14 moderate, 5 to 6 low, and 0 to 5 no anxiety. ${ }^{19}$

\section{Data Analysis}

Data management and analysis were performed using SPSS version 15.0 and the construction of graphs and charts was performed in Microsoft Excel version 14.0. In the statistical analysis, despite the abnormalities of the distribution (-Table 1), parametric tests were used (one-way ANOVA, Student's t-test, and Pearson's correlation) because of the expected sample of more than 100 observations. The chisquare test was used for categorical variables.

\section{Results}

The sum of all the children surveyed was 371. Their ages ranged between 2 and 17 years. The mean age and standard deviation of the children were $8.72 \pm 4.49$. All the respondents were distributed by age into three groups and by gender into two groups. ${ }^{14}$ The distribution is shown in - Table 2. 
According to the conducted statistical analysis, the mean DFA prevalence in children's population was $93.8 \%$. The total distribution of DFA in children's population is shown in - Table 2 and $\boldsymbol{- F i g}$. 1. Mean DFA prevalence in children aged 2 to 5 years was estimated as $100 \%$, in 6 to 11 years as $93.4 \%$, and in 12 to 17 years as $88.5 \%$. The mean DFA score in children's population was 11.85 . Mean DFA score in children aged 2 to 5 years was estimated as 13.51, in 6 to 11 years as 11.89 , and in 12 to 17 years as 10.27 .

Comparison of the Prevalence of DFA between the Genders According to a statistical analysis, differences in the prevalence of DFA between the genders were statistically significant (chi-square test $=15.61, \mathrm{df}=4, p=0.004$, effect size $(\mathrm{ES})=0.2$, power $=0.91$ ), and DFA was more often revealed ingirls $(-$ Fig. $\mathbf{1})$.

\section{Comparison of the Scores of DFA between the Genders}

The average DFA score for boys was $12.2 \pm 4.24$, and for girls, it was $11.5 \pm 4.51$ ( - Table 2 ), but those differences were not

Table 1 Distribution of the study's respondents by gender and age

\begin{tabular}{|l|l|l|l|}
\hline $\begin{array}{l}\text { Patients } \\
\text { characteristics }\end{array}$ & & $n$ & $\%$ \\
\hline \multirow{3}{*}{ Age (y) } & $2-5$ & 112 & 30.19 \\
\cline { 2 - 4 } & $6-11$ & 137 & 36.93 \\
\cline { 2 - 4 } & $12-17$ & 122 & 32.88 \\
\hline \multirow{2}{*}{ Gender } & Female & 192 & 51.75 \\
\cline { 2 - 4 } & Male & 179 & 48.25 \\
\hline Total & & 371 & 100 \\
\hline
\end{tabular}

statistically significant (Student's $t$-test, $t=1.62, \mathrm{df}=369$, $p=0.105, \mathrm{ES}=0.17$, and power $=0.37$ ).

\section{Comparison of the Prevalence of DFA between Age Groups}

According to a statistical analysis, the differences in DFA prevalence between age groups were statistically significant (chisquare test $=52.74, \mathrm{df}=8, p<0.0001, \mathrm{ES}=0.37$, power $=0.99$ ) with $100 \%$ probability of DFA occurrence in children of 2 to 5 years (-Fig. 2 ).

One-way ANOVA was used to determine the differences in DFA scores between the age groups (-Table 1). Age differences were statistically significant $(F[2,368]=17.3$, $p<0.0001, E S=0.29$, power $=0.99$ ). For post hoc calculations, Tukey's honestly significant difference was used. All groups had statistically significant differences from each other. DFA scores were most pronounced in children of 2 to 5 years.

\section{Correlation}

To understand how scores depend on age, Pearson's correlation was used. The test showed a negative correlation $\left(r=-0.32, t=-6.543, p<0.0001, R^{2}=0.32\right.$, power $\left.=0.99\right)$.

\section{Identification of the Prevalent Item in the MDAS Questionnaire}

To determine the dominant element in the MDAS questionnaire, the sum of the points for each element was calculated using the chi-square test. According to the results, the sum of those points varied greatly for different questions (chisquare test $=141.76, \mathrm{df}=4, p<0.0001, \mathrm{ES}=0.18$, power $=0.8$ ) with questions 3 and 5 scoring the maximum number of points.

Table 2 DFA scores in children's population

\begin{tabular}{|l|l|l|l|l|l|l|l|l|}
\hline \multicolumn{2}{|c}{} & Size & Mean & Median & SD & SE & \multicolumn{2}{l|}{ Normality test (Shapiro-Wilk) } \\
\cline { 3 - 9 } & & & & & & & W-statistic & $p$-Value \\
\hline \multirow{3}{*}{ Age (y) } & $2-5$ & 112 & 13.51 & 13.0 & 4.36 & 0.41 & 0.96 & 0.003 \\
\cline { 2 - 9 } & $6-11$ & 137 & 11.89 & 11.0 & 4.86 & 0.42 & 0.93 & $<0.001$ \\
\cline { 2 - 9 } & $12-17$ & 122 & 10.27 & 11.0 & 3.16 & 0.29 & 0.95 & $<0.001$ \\
\hline \multirow{2}{*}{ Gender } & Female & 192 & 12.20 & 11.5 & 4.25 & 0.31 & 0.95 & $<0.001$ \\
\cline { 2 - 9 } & Male & 179 & 11.46 & 11.0 & 4.52 & 0.34 & 0.95 & $<0.001$ \\
\hline
\end{tabular}

Abbreviations: DFA, dental fear and anxiety; SD, standard deviation; SE, standard error.

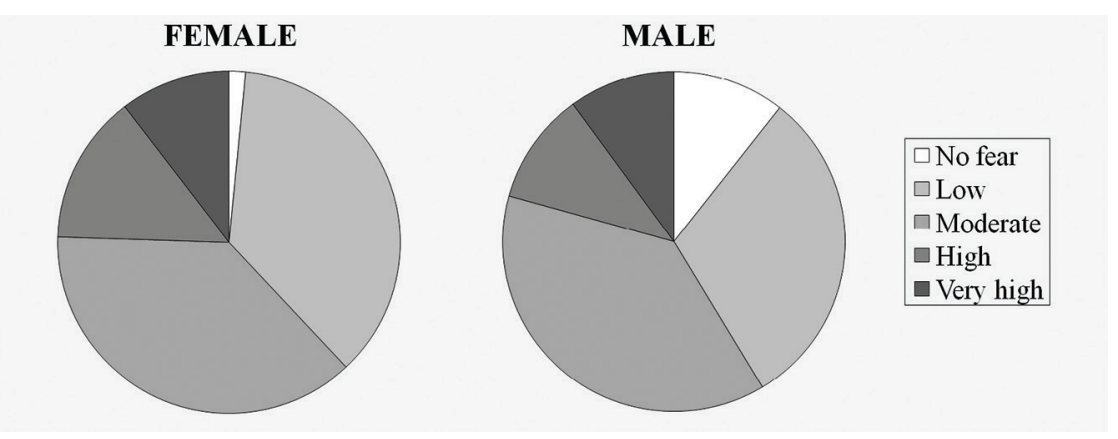

Fig. 1 Dental fear and anxiety scores and prevalence in males and females. 


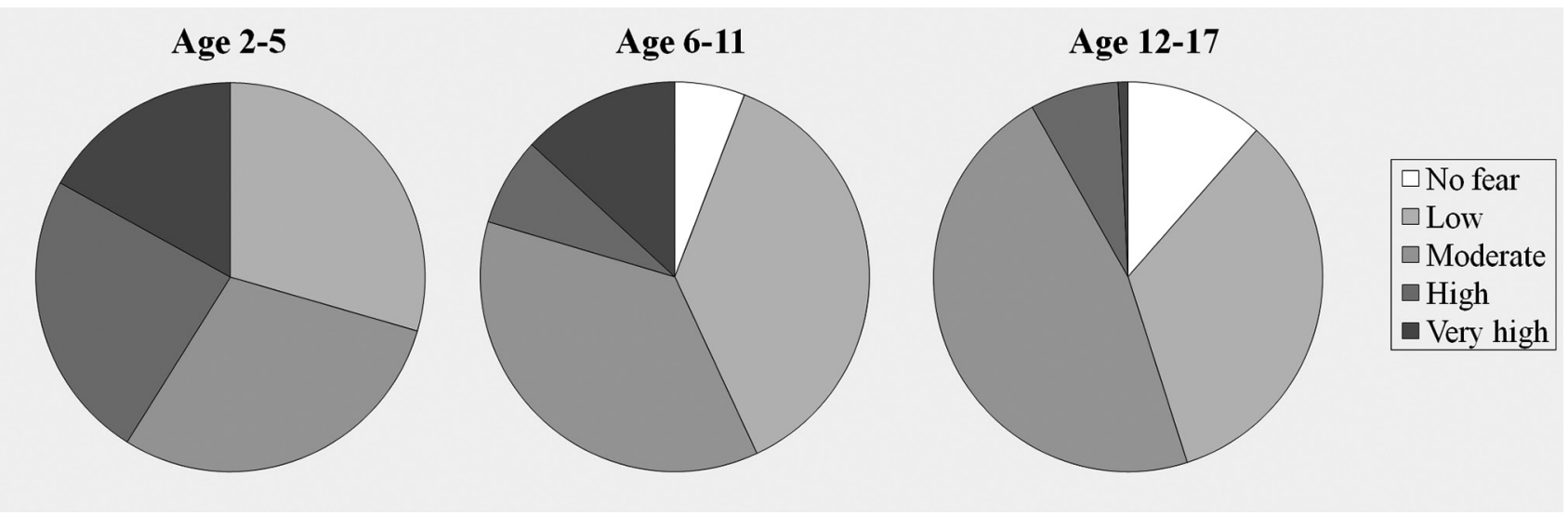

Fig. 2 Dental fear and anxiety prevalence in age groups.

\section{Discussion}

Children's DFA has been recognized as a source of serious health problems and may lead to an avoidance of seeking dental care or disruptive behavior during treatment. ${ }^{11}$ The data obtained in the present study have shown that $93.8 \%$ of the Russian child population suffer from moderate (11.85) levels of DFA, possibly interfering with dental treatment (-Table 2). The revealed DFA frequency exceeded the typical for European countries, values usually not outreaching $25 \%{ }^{6}$

It is considered that girls are more fearful than boys, ${ }^{2,20,21}$ and some studies support these findings, while others do not. ${ }^{22,23}$ In our study, we found that DFA was more often revealed in girls (-Fig. 1); however, the differences in mean DFA scores between genders were not statistically significant.

According to the obtained results, differences in the DFA prevalence between various age groups were statistically significant and the youngest children aged 2 to 5 years were most fearful with a $100 \%$ probability of DFA occurrence. The highest levels of DFA (13.51 \pm 4.36$)$ were also detected in this group of children (2-5 years). With that, the studies using MDAS across young children are rare, which makes it difficult to compare the obtained data with the literature ones. The mean score of DFA in the children of 6 to 11 years $(11.89 \pm$ 4.84) was higher than those reported by the vast majority of researchers, ${ }^{24,25}$ but lower than the values reported by Kumar et al (2019). ${ }^{19}$ The mean score of DFA in the children of 12 to 17 years $(10.27 \pm 3.16)$ was lower than the values found in the literature. ${ }^{26}$ Generally, these findings are consistent with the reports that DFA seems to decrease with increasing age. ${ }^{4,27}$ Beyond the processes of growing up and critical thinking development, this can be explained by the fact that the majority of children have been observed in the exact dental clinic from early childhood. Therefore, even if initially their level of DFA was high, over time, their DFA levels could decrease due to obtaining the necessary and timely treatment. ${ }^{2}$

The results of the study confirm the necessity of the DFA evaluation before dental treatment so that each child can be managed distinctively based on the reasons, which induce fear. $^{28}$ According to the obtained results, children were more afraid of "tooth drilling" and "injection of local anesthesia" than other factors mentioned in the questionnaires. It is interesting that "injections" and "drilling" are the most anxiety-provoking items in other studies conducted in various cultures as well. ${ }^{18,28}$ This pattern is traced among different ages and regardless of the questionnaire used to measure DFA and indicates that these anxiety factors remain constant despite a different general level of fear in different cultures. ${ }^{18}$ Administering local anesthesia by injection is still the most common method used in dentistry with the pain occurring as a result of the initial needle penetration into tissues, needle movement to the spot of anesthetic injection, and tissue swelling caused by the anesthetic injection. ${ }^{29}$ Thus, there is a need for a more comfortable and pleasant means of achieving local anesthesia before dental procedures. ${ }^{30,31}$ Among the promising approaches could be warming, buffering, precooling the injection, vibration using special devices, distraction techniques, application of topical anesthesia, and use of computer-controlled anesthesia delivery system (e.g., Wand). ${ }^{30-33}$

The results of the study emphasize that pediatric dentists should focus on the psychological aspects that the treatment can cause, thus, preventing painful and traumatic experiences. $^{34,35}$

This current study presents some limitations. First, based on the availability and accessibility of participants, we used a convenience sample, which could limit the generalizability of our results to the broader population. The data gathering procedure used may be the second limitation of the study. Children completed the questionnaire in a waiting room, where their parents were present, and thus, lack of privacy could have affected questionnaire completion. To minimize recall bias in our study, the children and the parents were given enough time to recall and answer the questionnaires. According to the results, the participants indicated DFA scores higher than the expected range for similar population. ${ }^{6}$ This result may be due to recruiting the sample participants in the waiting room of a dental clinic, where children could be scared or suffered from a toothache. Third, the present study has the common problems of research using self-reported measures. Finally, the results of the cross-sectional correlational research do not provide definite information about the cause and effect relationships, and thus, the results of the present study must be treated with caution.

\section{Conflict of Interest}

None declared. 


\section{Acknowledgment}

The study was supported by the government contract of the Russian Federation with the Institute of Immunology and Physiology (AAAA-A18-118020690020-1).

\section{References}

1 Klingberg G, Broberg AG. Dental fear/anxiety and dental behaviour management problems in children and adolescents: a review of prevalence and concomitant psychological factors. Int J Paediatr Dent 2007;17(6):391-406

2 Alshoraim MA, El-Housseiny AA, Farsi NM, Felemban OM, Alamoudi NM, Alandejani AA. Effects of child characteristics and dental history on dental fear: cross-sectional study. BMC Oral Health 2018;18(1):33

3 Setiawan AS, Kendhawati L, Agustiani H. Relational model between parental dental belief and formation of dental fear among preschool children in Indonesia. Eur J Dent 2019;13(3):426-431

4 ten Berge M, Veerkamp JS, Hoogstraten J, Prins PJM. Childhood dental fear in the Netherlands: prevalence and normative data. Community Dent Oral Epidemiol 2002;30(2):101-107

5 Baier K, Milgrom P, Russell S, Mancl L, Yoshida T. Children's fear and behavior in private pediatric dentistry practices. Pediatr Dent 2004;26(4):316-321

6 Luoto A, Lahti S, Nevanperä T, Tolvanen M, Locker D. Oralhealth-related quality of life among children with and without dental fear. Int J Paediatr Dent 2009;19(2):115-120

7 Lee CY, Chang YY, Huang ST. Prevalence of dental anxiety among 5- to 8-year-old Taiwanese children. J Public Health Dent 2007;67(1):36-41

8 Nguyen MS, Nguyen TT, Nguyen BB, Saag M, Olak J. Dental fear and anxiety in Estonian and Vietnamese schoolchildren: a comparative study of two populations. Clin Exp Dent Res 2018;4(5):182-188

9 Armfield JM. How do we measure dental fear and what are we measuring anyway? Oral Health Prev Dent 2010;8(2):107-115

10 Torriani DD, Ferro RL, Bonow ML, et al. Dental caries is associated with dental fear in childhood: findings from a birth cohort study. Caries Res 2014;48(4):263-270

11 Eitner S, Wichmann M, Paulsen A, Holst S. Dental anxiety-an epidemiological study on its clinical correlation and effects on oral health. J Oral Rehabil 2006;33(8):588-593

12 Armfield JM. What goes around comes around: revisiting the hypothesized vicious cycle of dental fear and avoidance. Community Dent Oral Epidemiol 2013;41(3):279-287

13 Vandenbroucke JP, von Elm E, Altman DG, et al; STROBE Initiative. Strengthening the Reporting of Observational Studies in Epidemiology (STROBE): explanation and elaboration. Int J Surg 2014;12(12):1500-1524

14 Frakking FNJ, van der Lee JH, Klassen TP, Offringa M. The StaR Child Health Project: Standards for Research with Children. 2009. Available at: http:// https://www.who.int/childmedicines/publications/GUIDANCECHILDHEALTH.pdf. Accessed January 30, 2020

15 BryzgalovAS, Sevbitov AV. Dental examinations and treatment of adolescents receiving hospital treatment subject to their psychic and emotional status [Osobennosti stomatologicheskogo obsledovaniya i lecheniya podrostkov, nakhodyashchikhsya $\mathrm{v}$ obshchesomaticheskom statsionare, $\mathrm{s}$ uchetom ikh psikho-emotsional'nogo statusa] Dental forum 2012;(1):47-49 [in Russian]. Available at: https://elibrary.ru/ item.asp?id=17795071\&.

16 Sevbitov AV, Makeeva IM, eds. Evaluation and Correction Methods for Dental Fear [Metody otsenki i korrektsii stomatofobii] [in Russian]. Moscow, Russia: MEDpress-inform; 2009
17 Newton JT, Edwards JC. Psychometric properties of the modified dental anxiety scale: an independent replication. Community Dent Health 2005;22(1):40-42

18 P BJ. Dental subscale of children's fear survey schedule and dental caries prevalence. Eur J Dent 2013;7(2):181-185

19 Kumar V, Goud EVSS, Turagam N, Mudrakola DP, Ealla KK, Bhoopathi PH. Prevalence of dental anxiety level in 6- to 12-year- old South Indian children. J Pharm Bioallied Sci 2019;11(Suppl 2) :S321-S324

20 Majstorovic M, Morse DE, Do D, Lim Ll, Herman NG, Moursi AM. Indicators of dental anxiety in children just prior to treatment. J Clin Pediatr Dent 2014;39(1):12-17

21 Arapostathis KN, Coolidge T, Emmanouil D, Kotsanos N. Reliability and validity of the Greek version of the Children's Fear Survey Schedule-Dental Subscale. Int J Paediatr Dent 2008;18(5):374-379

22 Singh P, Pandey RK, Nagar A, Dutt K. Reliability and factor analysis of children's fear survey schedule-dental subscale in Indian subjects. J Indian Soc Pedod Prev Dent 2010;28(3):151-155

23 Wogelius P, Poulsen S, Sørensen HT. Prevalence of dental anxiety and behavior management problems among six to eight years old Danish children. Acta Odontol Scand 2003;61(3):178-183

24 Boka V, Arapostathis K, Karagiannis V. Kotsanos N, van Loveren C, Veerkamp J. Dental fear and caries in 6-12 year old children in Greece. Determination of dental fear cut-off points. Eur J Paediatr Dent 2017;18(1):45-50

25 Carrillo-Díaz M, Crego A, Armfield JM, Romero M. Selfassessed oral health, cognitive vulnerability and dental anxiety in children: testing a mediational model. Community Dent Oral Epidemiol 2012;40(1):8-16

26 Abu-Ghazaleh SB, Rajab LD, Sonbol HN. Aljafari AK, Elkarmi RF, Humphris G. The Arabic version of the modified dental anxiety scale. Psychometrics and normative data for 15-16 year olds. Saudi Med J 2011;32(7):725-729

27 Klingberg G, Berggren U, Norén JG. Dental fear in an urban Swedish child population: prevalence and concomitant factors. Community Dent Health 1994;11(4):208-214

28 Rantavuori K, Lahti S, Hausen H, Seppä L, Kärkkäinen S. Dental fear and oral health and family characteristics of Finnish children. Acta Odontol Scand 2004;62(4):207-213

29 Sarapultseva M, Sarapultsev A, Medvedeva S, Danilova I. Structural damage to periodontal tissues at varying rate of anesthetic injection.J Dent Anesth Pain Med 2018;18(2):89-95

30 Peedikayil FC, Vijayan A. An update on local anesthesia for pediatric dental patients. Anesth Essays Res 2013;7(1):4-9

31 Garret-Bernardin A, Cantile T, D’Antò V, et al. Pain experience and behavior management in pediatric dentistry: a comparison between traditional local anesthesia and the Wand Computerized Delivery System. Pain Res Manag 2017;2017:7941238

32 Babaji P, Chauhan PP, Rathod V, Mhatre S, Paul U, Guram G. Evaluation of child preference for dentist attire and usage of camouflage syringe in reduction of anxiety. Eur J Dent 2017;11(4):531-536

33 Simon AK, Bhumika TV, Nair NS. Does atraumatic restorative treatment reduce dental anxiety in children? A systematic review and meta-analysis. Eur J Dent 2015;9(2):304-309

34 Appukuttan DP. Strategies to manage patients with dental anxiety and dental phobia: literature review. Clin Cosmet Investig Dent 2016;8:35-50

35 Dahlander A, Soares F, Grindefjord M, Dahllöf G. Factors associated with dental fear and anxiety in children aged 7 to 9 years. Dent J (Basel) 2019;7(3) 